\title{
The Effect of Topical Structure Analysis Instruction on University Students' Writing Quality
}

\author{
Somlak Liangprayoon ${ }^{1}$, Walaiporn Chaya ${ }^{2} \&$ Tipa Thep-ackraphong ${ }^{2}$ \\ ${ }^{1}$ Western Languages Program, Faculty of Humanities, Chiang Rai Rajabhat University, Chiang Rai, Thailand \\ ${ }^{2}$ Department of Western Languages, Faculty of Humanities, Srinakharinwirot University, Thailand \\ Correspondence: Somlak Liangprayoon Western Languages Program, Faculty of Humanities, Chiang Rai \\ Rajabhat University, Chiang Rai, 57100, Thailand. Tel: 668-5443-5091. E-mail: tonsoml@yahoo.com
}

Received: April 23, 2013 Accepted: May 20, 2013 Online Published: June 3, 2013

doi:10.5539/elt.v6n7p60 URL: http://dx.doi.org/10.5539/elt.v6n7p60

\begin{abstract}
Coherence is considered one of the characteristics of effective writing. Topical structure analysis (TSA) has been taught to students as a revision strategy to raise their awareness of importance of textual coherence and helps them clearly understand its concept. This study aimed to investigate the effectiveness of TSA instruction in improving university students' writing quality and to explore the proportions of topical progression in essays written by high and low proficiency students. It also examined the opinions of the students on TSA instruction. The participants consisted of two groups of 20 third year students majoring English Education at Chiangrai Rajabhat University. Data were collected through the pretest and the posttest of essay writing, two selected essays of high and low proficiency students, a questionnaire and an interview. The results indicated that TSA instruction had a significantly positive effect on students' writing quality. More specifically, TSA instruction was more beneficial to the low proficiency students than the high proficiency ones. Further, both successful and less succesful students employed the sequential progression the most in the essays. The students had positive opinions on TSA instruction.
\end{abstract}

Keywords: topical structure analysis, coherence, writing quality, writing instruction

\section{Introduction}

\subsection{Coherence}

Coherence has long been considered by many researchers as important quality of effective writing as it involved the global and logical meaning of the text and logical relations of the text (Bamberg, 1984; Grabe \& Kaplan, 1996; Lee, 2002). Coherence refers to the organization of written discourse of text by which all elements are clearly and logically joined to each other (Almaden, 2006). According to many studies on raters' perspectives of writing quality and studies on writing assessment, coherence is also viewed as one of the indicators of a good writing and is always included in most writing scoring rubrics (Chiang, 1999; Kobayashi \& Rinnert, 1996; Rinnert \& Kobayashi, 2001; Todd, Thienpermpool \& Keyuravonga, 2004; Witte \& Faigley, 1981).

However, there has been much evidence that EFL students have problems in fully comprehending the concept of writing coherence (Hirose, 2001; Lee, 2002). Previous studies have revealed that most ESL/EFL students still have difficulty in composing coherent and well-organized texts (Fujioka \& Shi, 2003; Hinds, 1990). A commonly identified problem of textual coherence in students' writing is digression, in which students include irrelevant examples or inappropriate supporting ideas in their writing (Strid, 1998). Digression not only impedes the logical development of ideas but also breaks the overall textual coherence (Fan \& Hsu, 2008). Thus, writing composed by ESL/EFL students is frequently considered disorganized and incoherent. It appears to be the result of the traditional approach to teaching writing which teachers tend to. This leads ESL/EFL students to focus more on the surface features instead of the discourse features of writing (Ferris \& Hedgcock, 1998; Grabe \& Kaplan, 1996; Hyland, 2007; Myers, 1997). Also, the students have no ideas how to revise their texts due to the ambiguous feedback given by teachers or peer. As Lee (2002) suggested, teachers' comments on textual coherence seems to be too vague and abstract and do not provide students concrete ideas or guidelines how to improve their writing to be coherent. Consequently, it is essential that textual coherence should be taught explicitly to help ESL/EFL students vividly understand its concept and be able to produce a good composition. 


\subsection{Topical Structure Analysis}

Topical structure analysis (TSA), proposed by Lautamatti (1987), has been proved to be one of the effective methods to raise students' awareness of textual coherence and helps them detect their own coherence problems in writing (Cerniglia, Medsker, \& Connor, 1990; Chiu, 2004; Connor \& Farmer, 1990; Fan \& Hsu, 2008; Sakontawut, 2003). According to Lautamatti (1987), TSA analyzes a sentence into two segments - a topic and a comment. The topic is defined as a part telling what the sentence is about or the main idea of a sentence; the comment refers to what is said about the topic. The topic of each sentence is a subtopic of the discourse topic of a text. By analyzing sentences into topics and comments, TSA, then, examines how sentence topics in a text semantically relate to the topic of discourse as a whole.

In order to identify how subtopics progress in a text to develop a discourse topic, Lautamatti suggested three types of topical progression. First, it is parallel progression (PP), in which the topic of the following sentence is identical or synonymous to the preceding one. By using this type of progression, the discourse topic of an essay is strengthened by means of repetition, pronominal forms, and synonyms of the topic used in the immediately preceding sentence (Schneider \& Connor, 1990). The second type is sequential progression (SP), in which the topic of the next sentence is the comment of the previous sentence, or a new different topic. The sequential progression helps to develop ideas of subtopics by adding details or giving examples. Finally, the topic in extended parallel progression (EPP) is the same as the topic of the previous sentence but is interrupted by some sequential progressions. When the extended parallel progression is used, it means that the writer provides a closure for readers and reminds them of main topic (Schneider \& Connor, 1990). The example of sentences topics in an essay and the three types of topical progression is illustrated below.

\section{Language and Community}

(1) When a human infant ${ }^{a}$ is born into any community in any part of the world, it has two things in common with any other infant, provided neither of them has been damaged in any way either before or during birth. (2) Firstly, and most obviously, new born children are completely helpless. (3) Apart from a powerful capacity to draw attention to their helplessness by using sound, there is nothing the new born child can do to ensure his own survival. (4) Without care from some other human being or beings, be it a mother, grandmother, sister, nurse, or human group, a child is very unlikely to survive. (5) This helplessness of human infants is in marked contrast with the capacity of many newborn animals to get to their feet within minutes of birth and run with the herd within a few hours. (6) Although young animals are certainly at risk, sometimes for weeks or even months after birth, compared with the human infant they very quickly develop the capacity to fend for themselves. (7) It would seem that this long period of vulnerability is the price that the human species has to pay for the very long period which fits man for survival as a species.

(8) It is during this very long period in which the human infant is totally dependent on others that it reveals the second feature which it shares with all other undamaged human infants, a capacity to learn language. (9) For this reason, biologists now suggest that language is "species specific" to the human race, that is to say, they consider the human infant to be genetically programmed in such a way that it can acquire language. (10) This suggestion implies that just as human beings are designed to see three-dimensionally and in colour, and just as they are designed to stand upright rather than to move on all fours, so they are designed to learn and use language as part of their normal development as well-formed human beings. (Lautamatti, 1987, p. 92)

1. a human infant

2. newborn children

3. the newborn child

4. a child

5. $\quad$ this helplessness

6.

7.

8. the human infant

9. language

10. human beings

Parallel Progression

(Lautamatti, 1987, p.96)

Note: Underlining indicates sentence topic.

Extended Parallel Progression 
At first, TSA was employed as an objective method to examine coherence and proportions of topical progression in students' texts (Almaden, 2006; Barabas \& Jumao-a, 2009; Carreon, 2006; Lautamatti, 1987; Simpson, 2000; Witte \& Faigley, 1981). More recently, it has been taught to students as a revision strategy to investigate their writing coherence (Cerniglia, et al., 1990; Chiu, 2004; Connor \& Farmer, 1990; Fan \& Hsu, 2008; Nunan, 1994; Sakontawut, 2003). According to Connor and Farmer's (1990) study, the implement of TSA as a self-revision strategy in ESL writing classes demonstrated that the students' writing improved after the revision, particularly in terms of coherence. Additionally, the students responded positively to TSA that it helped them check the meanings of their sentences and reminded them of the relationship between the meanings and the main topic and the purpose of their writings. Similar result was found in the study of Cerniglia, et al. (1990). They developed a computer- assisted instructional program to teach TSA to ESL students. It was found that this program helped students to connect the ideas in their writing and produce well-organized texts more effectively. In Sakontawut's (2003) study on a revision process of Thai college students after learning Functional Sentence Perspective (FSP), the results revealed slightly different scores between pretest and posttest. It was found that TSA could help students focus more on meanings and discourse-level features of writing in their revision. Moreover, a case study of Chiu (2004) on coaching a college English major student to develop coherence based upon TSA indicated that the student recognized the importance of coherence after learning and practicing TSA. Likewise, Fan and Hsu (2008) evaluated the feasibility of implementing TSA as a revision strategy for Taiwanese EFL graduate. The findings showed that the instruction has a positive effect on the students' revising process. Moreover, it was found that sequential progression was most frequently used in the students' writings.

It is evident that TSA could help students improve their writing quality, particularly in terms of coherence and organization of ideas. Nonetheless, the effectiveness in implementing TSA into writing instruction in EFL contexts and students' opinions on the implementation of TSA has been relatively unexplored, particularly in Thailand. Moreover, studies on the proportion of topical progression used in essays written by high and low proficiency students after learning TSA were scant. Consequently, the study on these issues should fill the gap and also shed more light onto EFL writing instruction.

\subsection{Purposes of the Study}

The present study aimed at threes purposes. It primarily aimed to investigate the effectiveness of topical structure analysis (TSA) instruction in improving university students' writing quality. Secondly, it examined the type of topical progressions which skilled and unskilled students used most frequently to develop the discourse of their essays. Finally, the study examined the opinions of the students on TSA instruction.

\subsection{Research Questions}

In order to achieve the purposes of the study, the following research questions were addressed:

1. Are the mean scores of overall writing quality and coherence on the posttest of the students in the experimental group significantly higher than those of the students in the control group?

2. Are the mean scores of overall writing quality and coherence of the essays of high and low proficiency students in the experimental group significantly different from those of the students in the control group?

3. What type topical progression is most frequently employed in highly-rated and low-rated essays in the experimental and the control groups?

4. What are the opinions of the students on learning TSA as a revision strategy in a writing classroom?

\section{Method}

\subsection{Participants}

The participants of the study consisted of two groups of 20 third-year students majoring English Education at Chiang Rai Rajabhat University (CRRU). During 12 weeks of teaching period, the students in the experimental group were taught the TSA in the Composition 1 course combined with the process approach to writing instruction while those in the control group learned the same writing course only through the process approach. Furthermore, five high proficiency and five low proficiency students in each group were selected based on their pretest scores by using the matching technique. These students were selected for qualitative data collection.

\subsection{Instruments}

The instruments in the research included (1) the pretest and the posttest of essay writing on the topic "What can you do to reduce the global warming in Thailand?", (2) the textbook titled Introduction to Academic Writing, $3^{\text {rd }}$ edition (Oshima \& Hogue, 2006), (3) two selected essays of subgroups in the experimental and the control groups, (4) the Essay Rating Scale for the TOEFL Test of Written English (Education Testing Service, 2000) and 
the Holistic Scale of Coherence (Bamberg, 1984), (5) a questionnaire on the students' opinions on TSA instruction and (6) an interview.

\subsection{Raters}

Three raters were invited to participate in this study in order to grade all of the students' written works. For the inter-rater reliability, the scores on the pretest and the posttest rated by the raters were analyzed using the Pearson Product-Moment Correlation Coefficient. There were relatively high correlations among the three raters (See Appendix A).

\subsection{Data Collection}

The data were collected from the written products of the participants in the experimental and the control groups. They included the pretest, the posttest and the first and the final drafts of the two selected essays - a classification and a comparison and contrast essay- of the skilled and unskilled students. All of these written products were rated by the three raters using the Essay Rating Scale for the TOEFL Test of Written English (ETS, 2000) and the Holistic Scale of Coherence (Bamberg, 1984). Moreover, the number of topical progression in the highly- and low-rated essays was analyzed by using the coding guidelines for topical structure analysis proposed by Schneider and Connor (1990) (See Appendix B). After the posttest, the questionnaire and the interview were carried out to gain information regarding the students' opinions on implementing TSA into a writing course. The interview provided in-depth information elicited from the high and low proficiency students in the experimental group.

\subsection{Data Analysis}

In data analysis, the mean scores of overall quality and coherence on the posttest of the participants in the experimental and the control groups were compared by using the independent t-test. Additionally, the independent t-test was conducted to compare the mean score of overall writing quality and coherence of the two selected writing between the successful and less unsuccessful students to examine whether TSA instruction better assisted high or low proficiency students to improve writing quality. Also, a number of each topical progression type found in the two selected essays was analyzed and compared using frequency and percentage. Moreover, the results of the questionnaire of the participants in the experimental group were analyzed by mean and standard deviation. Regarding the qualitative data from the interview of the high and low proficiency students in the experimental group, the results are reported in description.

\section{Results and Discussion}

\subsection{The Effectiveness of Topical Structure Analysis Instruction}

The analysis of the independent t-test revealed the differences of the mean score of overall writing quality and coherence on the posttest between the experimental group and the control group as shown in Table 1.

Table 1. Mean scores of overall quality and coherence on the posttest of the students in experimental and the control groups

\begin{tabular}{llllllll}
\hline \multirow{2}{*}{ Score } & \multirow{2}{*}{$n$} & \multicolumn{2}{l}{ Experimental Group } & \multicolumn{2}{l}{ Control Group } & \multirow{2}{*}{$t$} & \multirow{2}{*}{$p$} \\
\cline { 3 - 6 } & & $M$ & $S D$ & $M$ & $S D$ & & $0.003^{* *}$ \\
\hline Overall Quality & 20 & 3.48 & 0.68 & 2.85 & 0.57 & 3.17 & $0.003^{* *}$ \\
Coherence & 20 & 2.50 & 0.45 & 2.08 & 0.36 & 3.22 & \\
\hline
\end{tabular}

**Significant at the $\mathrm{p}<.01$ level

Table 1 illustrates that the mean score of overall writing quality on the posttest of the students in the experimental group was $3.48(S D=0.68)$ while that of the students in the control group was $2.85(S D=0.57)$. This indicates that the overall writing quality of the participants in the experimental group was significantly higher than that of the participants in the control group $(t(38)=3.17, p=.003)$.

Regarding coherence, Table 1 demonstrates that the mean score of the participants in the experimental group was $2.50(S D=0.45)$ whereas that of the control group was $2.08(S D=0.36)$. The results reveal that there was a significant difference of mean score of coherence between the two groups $(t(38)=3.22, p=.003)$. It can be concluded that the teaching of topical structure analysis (TSA) better assisted the students in improving their overall writing quality and coherence than did the process-based approach to writing instruction. 
With regard to the effect of TSA instruction on quality of writing of students with different proficiency levels, a comparison of mean scores of overall writing quality and coherence of the essays written by students in the experimental and control groups are presented in Table 2 and Table 3 respectively.

Table 2. Mean scores of overall writing quality of selected essays of high and low proficiency students

\begin{tabular}{llllllll}
\hline \multirow{2}{*}{ Students } & \multirow{2}{*}{$n$} & \multicolumn{2}{l}{ Experimental Group } & \multicolumn{2}{l}{ Control Group } & \multirow{2}{*}{$t$} & \multirow{2}{*}{$p$} \\
\cline { 2 - 6 } & & $M$ & $S D$ & $M$ & $S D$ & & 0.602 \\
\hline High Proficiency & 5 & 4.21 & 0.60 & 3.99 & 0.65 & 0.54 & $0.041^{*}$ \\
Low Proficiency & 5 & 3.15 & 0.35 & 2.40 & 0.59 & 2.44 & 0 \\
\hline
\end{tabular}

*Significant at the $\mathrm{p}<.05$ level

The results in Table 2 indicate that mean scores of overall writing quality of the unskilled students in the experimental group and the control group were significantly different $(t(8)=2.44, p=.041)$. The mean score of the students in the experimental group was $3.15(S D=0.35)$ while that of the students in the control group was $2.40(S D=0.59)$.

On the contrary, there was no significant difference in the mean score of the overall writing quality the essays between the skilled students in the two groups $(t(8)=0.54, p=0.602)$. The mean score of the high proficiency students in the experimental group was 4.21 $(S D=0.60)$ while that of the control group was $3.99(S D=0.35)$.

Table 3. Mean scores of coherence of selected essays of high and low proficiency students

\begin{tabular}{llllllll}
\hline \multirow{2}{*}{ Group } & \multirow{2}{*}{$n$} & \multicolumn{2}{l}{ Experimental Group } & \multicolumn{2}{l}{ Control Group } & \multirow{2}{*}{$t$} & \multirow{2}{*}{$p$} \\
\cline { 3 - 6 } & & $M$ & $S D$ & $M$ & $S D$ & & 0.097 \\
\hline High Proficiency & 5 & 3.10 & 0.38 & 2.72 & 0.26 & 1.88 & $0.042^{*}$ \\
Low Proficiency & 5 & 2.28 & 0.19 & 1.86 & 0.34 & 2.41 & 0.41 \\
\hline
\end{tabular}

*Significant at the $\mathrm{p}<.05$ level

Regarding coherence scores, Table 3 illustrates that the mean score of the high proficiency students in the experimental group was $3.10(S D=0.38)$ while that of students in the control group was $2.72(S D=0.26)$. For the low proficiency students, the mean score of coherence of the experimental group was $2.28(S D=0.19)$ whereas that of the control group was $1.86(S D=0.34)$.

The results demonstrate that mean score of coherence of the low proficiency students in the experimental group was significantly higher than that of the students in the control group $(t(8)=2.41, p=.042)$. In contrast, no significant difference between the high proficiency students in the two groups was found $(t(8)=1.88, p=$ 0.097).

The findings of this study were consistent to the previous studies that the students' writing quality, particularly coherence, improved after learning TSA (Chiu, 2004; Connor \& Farmer, 1990; Fan \& Hsu, 2008). This may be due to the explicit teaching of TSA as a revision strategy which focused the students on semantic relations between sentence topics and a discourse topic. This strategy emphasized a revision of the discourse features of writing. It also helped the students detect when there was digression from the discourse topic of essays so that they could rewrite and produce coherent texts.

More specifically, the present study revealed that TSA instruction was more beneficial to less successful students than successful ones. One explanation of this result is concerned with different levels of awareness and use of the writing process and strategies between high and low proficiency students. In previous research on the writing process of skilled and unskilled students (e.g, Bosher, 1998; Nunan, 1991; Roca de Larios, Murphy, \& Manchon, 1999; Zamel, 1983), it has been concluded that skilled L2 writers tend to spend more time to plan, revise and do writing tasks in the most effective way . Also, their main concerns were in the discourse levels like global content, organization, topic sentences, coherence and unity (Barkaoui, 2007; Nunan, 1991; Tsai, 2009).

Accordingly, it can be implied that prior to the treatment, the high proficiency students in the present study were 
already aware of and could control their writing process and strategies while writing and revising texts. They could plan, monitored and evaluated their essays and knew how to revise their essays both at the surface and the discourse levels. Consequently, there were no significance differences of writing performance between the skilled students in the experimental and control groups.

With regard to low proficiency students, when writing, they perform differently from the high proficiency students regarding the writing process and strategies used in each writing step. In the revision process, the unskilled students mainly concerned the surface level of writing including grammar, word use, and translation rather than the discourse of writing. The emphasis on these writing features resulted in ineffective writing according to many criteria for writing evaluation (EST, 2000; Rinnert \& Kobayashi, 2001; Todd, Thienpermpool $\&$ Keyuravonga, 2004). Therefore, teaching TSA as a revision strategy to low proficiency students could assist them to focus on the discourse structure of writing, particularly in terms of coherence when revising their essays. This led to better quality of writing of the low proficiency students in the experimental group than those in the control group.

\subsection{Proportion of Topical Progression in Selected Essays of High and Low Proficiency Students}

This study also investigated the proportion of each type of topical progression to determine the type which was the most frequently used in the high and low scoring writing of students in the experimental and the control groups. The findings demonstrate that both high and low proficiency students in the two groups used the sequential progression the most in their essays.

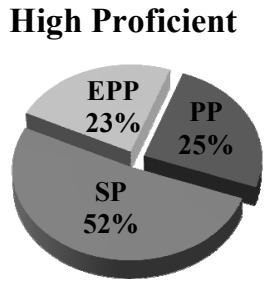

The Experimental Group

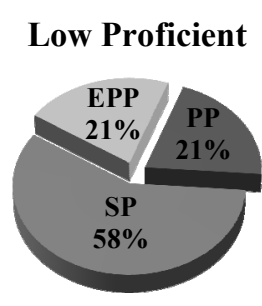

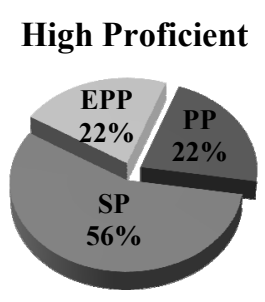

The Control Group

Figure 1. Percentage of topical progression of the experimental and the control groups

Note: PP = Parallel Progression, $\mathrm{SP}=$ Sequential Progression and EPP $=$ Extended Parallel Progression

As illustrated in Figure 1, the percentages of sequential progression used by high and low proficiency students in the experimental group were $52 \%$ and $58 \%$, respectively. Moreover, the percentage of the parallel progression used by the successful students (25\%) was slightly higher than that used by the less successful group (21\%). Also, the high proficiency students employed more extended parallel progression than did the low proficiency group ( $23 \%$ and $21 \%$ respectively).

Similar to the results of the experimental group, the type of topical progression most frequently used by the students in the control group was the sequential progression- $56 \%$ by the high proficiency students and $68 \%$ for the low proficiency group. While the percentage of the sequential progression used by the low proficiency students was higher, their use of the parallel progression $(15 \%)$ and the extended parallel progression (18\%) was rather less than those of the proficiency students ( $22 \%$ and $21 \%$ respectively).

According to the results in Figure 1, it can be concluded that the proportions of topical progressions used the highly-rated essays were not different from those used in the low-rated ones. That is, in order to develop the discourse of their texts, the students in the experimental and the control groups tended to introduce a new subtopic in each T-unit rather than repeating the same topic or "developing an idea as well as bringing readers back to the main idea to achieve a closure" (Cerniglia et al., 1990, p. 238).

The results of this study are in line with some previous studies (Barabas \& Jumao-a, 2009; Carreon, 2006; Fan \& Hsu, 2008; Schneider \& Connor, 1990) which revealed that EFL students employed sequential progression the most in their essays. A plausible explanation for the highest number of sequential progression used is the text type or the rhetorical mode of the essay. In Ghabanchi and Alavi's (2011) study, it was found that there was a relationship between the rhetorical mode of text and topical progression used. The students' two selected essays 
in the present study were the classification and the comparison and contrast essays of which the rhetorical mode is exposition. According to Oshima and Hogue (2006), when writers write expository essays, they develop their ideas in the essays by adding details and giving examples of the topics they discuss. Consequently, the sequential progression as suggested by Schneider and Connor (1990, p. 416) that "it helps to develop individual topics by adding details to an idea" is most frequently employed in the essays of the students in this study.

According to the findings in Figure 1, it can be further explained that the high proficiency students in the two groups introduced fewer new subtopics in their essays than did the low proficiency group as indicated by the lower percentage of use of the sequential progression. This could result in the better quality of their essays, particularly in terms of coherence. As Connor and Farmer (1990) indicated, if a writer logically makes use of the sequential progression and make good balance with the other types of topical progression, it may add to the overall good quality. Additionally, as illustrated in Figure 1, higher percentage of the parallel and the extended parallel progression used by the students in the experimental group when compared to the students with the same proficiency levels in the control group should lead to a noteworthy conclusion. That is to say, beside good balance in the use of the sequential progression with the other types, essays are perceived as better quality and particularly more coherent when the use of the parallel progression is in good balance with the use of the extended parallel one (Burneikaite \& Zabiliute, 2003).

\subsection{Students' Opinions on TSA Instruction}

The analysis of results from the questionnaire of students' opinion on implementing TSA instruction into a writing class revealed that the total mean of agreement level of the students in the experimental group was 4.20 $(S D=0.53)$. This result indicates that the students in the experimental group had positive opinions on implementing TSA into their writing class.

Table 4. Opinions of the students in the experimental group on TSA instruction

\begin{tabular}{|c|c|c|c|}
\hline & Statements & $M$ & $S D$ \\
\hline 1. & The class activity and teaching process were interesting. & 3.95 & 0.51 \\
\hline 2. & The teaching materials were beneficial and easy to understand. & 4.15 & 0.37 \\
\hline 3. & $\begin{array}{l}\text { After learning TSA instruction, I become more aware of the importance of } \\
\text { coherence in writing and understand its concepts clearly. }\end{array}$ & 4.50 & 0.51 \\
\hline 4. & $\begin{array}{l}\text { Learning through TSA instruction helped me identify which sentences were } \\
\text { relevant or irrelevant to the main topic of the text. }\end{array}$ & 4.00 & 0.65 \\
\hline 5. & After learning this course, I knew how to organize the ideas in an essay coherently. & 4.20 & 0.52 \\
\hline 6. & $\begin{array}{l}\text { Learning through TSA instruction helped me identify the topic of each sentence, so } \\
\text { I could check the coherence in my essays by myself. }\end{array}$ & 4.20 & 0.62 \\
\hline 7. & $\begin{array}{l}\text { After learning TSA, I knew how to revise my essay and make all the ideas in the } \\
\text { essay related to the main topic. }\end{array}$ & 4.20 & 0.52 \\
\hline 8. & TSA was an effective strategy for revising of written texts. & 4.30 & 0.57 \\
\hline 9. & The process of TSA was easy to follow when I revised my essays. & 4.20 & 0.41 \\
\hline 10. & $\begin{array}{l}\text { The combination of the teacher's feedback and TSA instruction helped me write an } \\
\text { essay more coherently }\end{array}$ & 4.25 & 0.64 \\
\hline & TOTAL & 4.20 & 0.53 \\
\hline
\end{tabular}

As illustrated in Table 4, the highest mean was the statement asking whether the students become more aware of the importance of coherence in writing and understand its concept clearly after learning this course $(M=4.50$, $S D=0.51)$. The lowest level of agreement was whether the class activity and teaching process were interesting $(M=3.95, S D=0.51)$.

Since most of the statements in the questionnaire were about students' understanding and awareness of textual coherence in writing, the relatively high means of agreement level suggests that the students in the experimental group strongly agreed that TSA instruction could enhance them to produce coherent texts.

\subsection{Results of the Interview}

The interview of five high and five low proficiency students was conducted to gain in-depth information about 
the students' opinions and to support the results from the questionnaire. The results are presented in description under the following headings.

\subsubsection{Benefits of TSA Instruction}

When asked how TSA instruction was helpful to their writing, the participants stated that practicing TSA was beneficial to their writing skill. It was a self-revision strategy which helped them understand the concept of textual coherence more clearly. Both skilled and unskilled students reported that after learning TSA they became more aware of textual coherence that all ideas in the texts had to be connected and related to the topic of discourse. Importantly, TSA assisted them rewrite their writing more coherently. A high proficiency student expressed "When I found too many sequential progressions, I realized that there were many new subtopics leading to irrelevant ideas to the main topic. Then, I stopped writing and reread my essay to find a point to rewrite". One low proficiency student added "TSA helps me examine whether my writing was coherent or not. It helps me focus on the scope of the discourse topic when writing".

These results are consistent with those reported in Connor and Farmer's (1990) study. They applied TSA to teach ESL college students at the intermediate and advanced levels, and their study yielded positive results. In the present study, the students' responses suggest that TSA can be implemented into EFL writing instruction and is accepted as a useful means of examining coherence.

\subsubsection{Problems and Difficulties in Learning TSA}

In responding to the question about problems and difficulties in learning academic writing through TSA instruction, most participants informed that they had difficulty identifying sentence topics in their essays. The followings are some of students' responses.

- $\quad$ The most difficult part in TSA was identifying a topic in each T-unit, but I could identify the types of topical progression of each topic when charting a diagram.

- Sometimes I couldn't find a topic of a T-unit because I was not sure what it was talking about.

- Although topical analysis is a good self-revision technique, it is difficult for me to do it alone without the teacher's help. I'm afraid that my analysis may be incorrect as I'm still weak in writing. I need more practice".

As shown in the examples, the difficulty originated from lack of practice before they mastered the strategy. This may be due to the short period of practice TSA as a self-revision strategy which was one of the limitations of the study. As TSA is a new revision strategy for the participants in this study, they needed more time to familiarize the concept of TSA and then gradually gain clear understanding. The length of time for practicing TSA before the students applied the strategy to their revision was 4 weeks out of the 12 weeks of teaching period. This may not be enough for students to practice the strategy since acquiring any new concepts in other languages takes a great deal of time, and studying writing process and strategies in foreign languages is particularly complicated.

In addition, the difficulty in identifying sentence topics also resulted from students' lack of self-confidence and opportunity to analyze the essays on their own. This is partly due to a cultural characteristic of the EFL students to be dependent on teachers' supports in learning (Cheng, 2000; Javis \& Atsilarat, 2004; Nonkukhetkhong, 2006).

\subsubsection{Perception of Learning TSA}

When asked what they thought about the teaching process and class activities, all of the students in the experimental group stated that they preferred the teacher's feedback given to them in the first drafts. A student reported "The teacher's feedback helped me rewrite and corrected all mistakes properly. The teacher also suggested them what to be revised in their written texts".

Moreover, a type of teacher's feedback that the students needed the most was grammar and vocabulary and the second was content and organization. Interestingly, some of the less successful group would like to receive feedback on content and organization. They stated "When assigned to write, I knew what to write, but not how to write. Consequently, teacher's feedback could guide me how to write essays smoothly from the beginning to the end".

In brief, the participants, although learning TSA as a self-revision strategy, still need teacher's feedback when revising their written texts both at the surface and the discourse levels. According to Tsui and Ng (2000) it is because in their cultures EFL students view the teacher as the only one who has authority and competence to provide them feedback which they can use for their subsequent revision. Moreover, Myers (1997) suggested that ESL/EFL students need to be helped with vocabulary and sentence-level syntax when writing L2 composition. From her experience in teaching ESL writing, Myers revealed that her students' real problem is insufficient 
linguistic knowledge to write fluently in the target language, but not lack of ideas to write. Thus, it is suggested that in teachers' feedback is needed at the early stage of TSA training and writing instruction.

\section{Limitations and Recommendations}

\subsection{Limitations}

A number of limitations of the study are worthy of note. First, teaching TSA as a revision strategy had its shortcoming. As the students applied this strategy to their revision process which is the last stage of writing process, mere teaching of TSA strategy does not help students examine other important aspects of writing such as purpose of writing and audience. This may lead students to produce texts which each subtopic is related to the discourse topic, but not to the purpose of writing. Second, this study investigated the topical progression used in only two types of essays; it did not cover all rhetorical modes of writing. Thus, the proportions of each topical progression type may be varied in different modes of writing. Finally, the participants of the study were purposively selected, and their levels of proficiency ranged from lower-intermediate to intermediate. The findings can be limitedly generalized and are specific to the particular groups of students with the similar context to this study.

\subsection{Recommendations for Further Research}

Despite of the limitations, the results of this study indicated directions for further studies. First, future research should integrate TSA as revision strategy into a teaching method which covers all aspects of writing process starting from the planning stage to the end of the process. Second, this study investigated the effectiveness of TSA instruction in improving the writing quality in the essays of university students. Future research should attempt to study the effects of this method with students in various levels of education and with different levels of English proficiency to determine the most appropriate levels of the students for the implementation of TSA instruction. Third, this study revealed the proportions of topical progression in only two types of the essay, classification and comparison and contrast. Other research on TSA should be conducted to analyze other types of essays to determine the proportions of topical progression. Moreover, research on the effect of TSA instruction on the writing quality and proportions of topical progression in texts of students in other fields of study should be investigated. The results may reveal the effectiveness of implementing TSA instruction into writing instruction in various fields of study. Finally, in future research, there should be a larger number of participants with various levels of language proficiency in order to gain more samples so that the effectiveness of TSA instruction can be generalized by more relevant and statistically valid information.

\section{Conclusion}

This study offered an alternative teaching method, the TSA instruction, to assist students to produce coherent writing. The improvement of students' writing quality and positive opinions of the students to the implementation of TSA into a writing class demonstrated benefits of explicitly training of writing strategies to the EFL students. The results suggested teaching TSA as a self-revision strategy is effective for improving writing coherence and promoting independent and autonomous EFL student writers.

\section{Acknowledgements}

The authors would like to express our deepest gratitude to the Office of the Higher Education Commission, Ministry of Education Thailand for a government scholarship titled Strategic Consortia for Capacity Building of University Faculties and Staff. This study would not be completed without this scholarship.

\section{References}

Almaden, D. O. (2006). Analysis of the topical structure of paragraphs written by Filipino students. The Asia-Pacific Research, 15, 127-153.

Bamberg, B. (1984). Assessing Coherence: A Reanalysis of Essays Written for the National Assessment of Educational Progress, 1969-1979. Research in the Teaching of English, 18, 305-319.

Barabas, C. D., \& Jumao-as, A. G. (2009). Topical Structure Analysis: The Case of the Essays Written by Cebuano Multilingual Students. Retrieved February 9, 2013, from http://www.academia.edu/2147694/ Topical_Structure_Analysis_The_Case_of_the_Essays_Written_by_Cebuano_Multilingual_Students-1.pdf

Barkaoui, K. (2007). Revision in second language writing: What teachers need to know. TESL Canada Journal, $25,81-92$. 
Bosher, S. (1998). The composing processes of three Southeast Asian writers at the post-secondary level: An exploratory study. Journal of Second Language Writing, 7, 205-241. http://dx.doi.org/10.1016/S10603743(98)90013-3

Carreon, M. C. (2006). Unguarded patterns of thinking: Physical and topical structure analysis of students journals. The Asia-Pacific Research, 15, 155-182.

Cerniglia, C. S., Medsker, K. L., \& Connor, U. (1990). Improving coherence by using computer-assisted instruction. In Ulla C., \& Ann. M. J (Eds.), Coherence in Writing: Research and pedagogical perspectives (pp. 227-241). Alexandria, VA: Teachers of English to Speakers of Other Language, Inc.

Cheng, X. (2000). Asian students' reticence revisited. System, 28, 435-46. http://dx.doi.org/10.1016/S0346-251X(00)00015-4

Chiang, S. (1999). Assessing grammatical and textual features in L2 writing samples: The case of French as a foreign language. The Modern Language Journal, 83, 219-232. http://dx.doi.org/10.1111/0026-7902.00017

Chiu, Y. F. (2004). Coaching a student to develop coherence based upon topical structure analysis: A case study. Journal of Language and Learning, 2, 154-170.

Connor, U., \& Farmer, M. (1990). The teaching of topical structure analysis as a revision strategy for ESL writers. In B. Kroll (Ed.), Second Language Writing: Research insights for the classroom (pp. 126-139). Cambridge University Press. http://dx.doi.org/10.1017/CBO9781139524551.013

Cumming, A. (1989). Writing expertise and second language proficiency. Language Learning, 39, 81-141. http://dx.doi.org/10.1111/j.1467-1770.1989.tb00592.x

Educational Testing Service. (2000). Computer-based TOEFL score user guide. Retrieved March 18, 2009, from http://www.ets.org/Media/Tests/TOEFL/pdf/989551.pdf

Faigley, L., \& Witte, S. (1981). Analyzing revision. College Composition and Communication, 32, 365-387. http://dx.doi.org/10.2307/356602

Fan, Y., \& Hsu, A.Y. (2008). Topical structure analysis as alternative learning strategy of coherent writing. Journal of Applied English, 1, 115-137.

Ferris, D., \& Hedgcock, J. S. (1998). Teaching ESL composition: Purpose, process, practice. NJ: Lawrence Erlbaum Associates.

Fujioka, K., \& Shi, J. (2000). ESL students' problems in academic writing. ICU Language Research Bulletin, 15, $1-15$.

Ghabanchi, Z., \& Avali, S. Z. (2011). The relationship between types of paragraphs and topic progression used in paragraphs written by Iranian EFL students. Journal of International Education Research-Fourth Quarter, 7, 39-46.

Grabe, W., \& Kaplan, R. B. (1996). Theory and practice of writing. New York, NY: Longman.

Hinds, J. (1990). Inductive, deductive, quasi-inductive: Expository writing in Japanese, Korean, Chinese and Thai. In Connor, U., \& Jones, A. (Eds.), Coherence in writing: Research and pedagogical perspectives (pp. 81-109). Alexandria, VA: TESOL.

Hirose, K. (2001). Realizing a giant first step toward improved English writing: A case in a Japanese university. In I. Leki (Ed.), Academic Writing Programs (pp. 35-46). Washington, DC: TESOL.

Hyland, K. (2007). Genre pedagogy: Language, literacy and L2 writing instruction. Journal of Second Language Writing, 16, 148-164. http://dx.doi.org/10.1016/j.jslw.2007.07.005

Jarvis, H., \& Atsilarat, S. (2004). Shifting paradigms: form a communicative to a context-based approach. Asian EFL Journal, 6, 1-23.

Kobayashi, H., \& Rinnert, C. (1996). Factors affecting composition evaluation in an EFL context: cultural rhetorical pattern and readers' background. Language Learning, 46, 397-437.

Lautamatti, L. (1987). Observations on the development of the topic of simplified discourse. In Connor, U., \& Kaplan, R. B. (Eds.), Writing across languages: Analysis of L2 text (pp. 87-114). Reading, MA: Addison-Wesley Publishing Company, Inc.

Lee, I. (2002). Teaching coherence to ESL students: A classroom inquiry. Journal of Second Language Writing, $11,135-159$. 
Myers, S. (1997). Teaching writing as a process and teaching sentence-level syntax: reformulation as ESL composition feedback. TESL-EJ Journal, 2. Retrieved August, 3, 2009, from http://www.zait.uni-bremen.de/ wwwgast/tesl_ej/ej08/a2.html

Nonkukhetkhong, R., B. Baldauf Jr, \& K. Moni. (2006). Learner Centeredness in Teaching English as a Foreign Language. Paper Presented at 26 Thai TESOL International Conference, Chiang Mai, Thailand, 19-21 January 2006, 1-9.

Nunan, D. (1994). On the psychological plausibility of 'topic' as a construct in research on writing. Hong Kong Paper in Linguistics and Language Teaching, 17, 25-37.

Oshima, A., \& Hogue, A. (2006). Introduction to academic writing (3rd ed.). New York, NY: Longman.

Rinnert, C., \& Kobayashi, H. (2001). Differing perceptions of EFL writing among readers in Japan. The Modern Language Journal, 85, 189-209. http://dx.doi.org/10.1111/0026-7902.00104

Roca de Larios, J., Murphy, L., \& Manchon, R. (1999). The use of restructuring strategies in EFL writing: A study of Spanish learners of English as a second language. Journal of Second Language Writing, 8, 13-44. http://dx.doi.org/10.1016/S1060-3743(99)80111-8

Sakontawut, N. (2003). Functional sentence perspective and second language composition: A case study of revision process in a writing workshop for Thai college students (Doctoral dissertation, Indiana University of Pennsylvania). Retrieved July 3, 2011, from http://202.28.199.34/multim/3080961.pdf

Schneider, M., \& Connor, U. (1990). Analyzing topical structure in ESL essays: Not all topics are equal. Studies in Second Language Acquisition, 12, 411-427. http://dx.doi.org/10.1017/S0272263100009505

Simpson, J. M. (2000). Topical structure analysis of academic paragraphs in English and Spanish. Journal of Second Language Writing, 9, 293-309. http://dx.doi.org/10.1016/S1060-3743(00)00029-1

Todd, R.W., Thienpermpool, P., \& Keyurawong, S. (2004). Measuring the coherence of writing using topical-based analysis. Assessing Writing, 9, 85-104. http://dx.doi.org/10.1016/j.asw.2004.06.002

Tsai, H. M. (2009). Examining metacognitive performance between skilled and unskilled writers in an integrated EFL writing class. The $26^{\text {th }}$ International Conference on English Teaching and Learning in the R.O.C. (pp. 678-689). Taipei: Crane. Retrieved February 21, 2013, from www.cit.edu.tw/110/20100814053319.pdf

Tsui, A. B. M., \& Ng, M. (2000). Do secondary L2 writers benefit from peer comments? Journal of Second Language Writing, 9, 147-170. http://dx.doi.org/10.1016/S1060-3743(00)00022-9

Witte, S. P., \& Faigley, L. (1981). Coherence, cohesion, and writing quality. College Composition and Communication, 32, 19-204. http://dx.doi.org/10.2307/356693

\section{Appendix A}

Inter-rater Reliability of Overall Writing Quality and Coherence on Pretest and Posttest

\begin{tabular}{|c|c|c|c|c|c|}
\hline Score & & $\begin{array}{l}\text { Pearson } \\
\text { Correlation }\end{array}$ & Rater 1 & Rater 2 & Rater 3 \\
\hline \multirow[t]{6}{*}{ Overall Quality } & Pretest & Rater 1 & 1 & $0.745^{* *}$ & $0.864 * *$ \\
\hline & & Rater 2 & $0.745^{* *}$ & 1 & $0.693^{* *}$ \\
\hline & & Rater 3 & $0.864 * *$ & $0.693^{* *}$ & 1 \\
\hline & Posttest & Rater 1 & 1 & $0.789^{* *}$ & $0.837^{* *}$ \\
\hline & & Rater 2 & $0.789 * *$ & 1 & $0.840^{* *}$ \\
\hline & & Rater 3 & $0.837 * *$ & $0.840^{* *}$ & 1 \\
\hline \multirow[t]{6}{*}{ Coherence } & Pretest & Rater 1 & 1 & $0.715^{* *}$ & $0.694 * *$ \\
\hline & & Rater 2 & $0.715^{* *}$ & 1 & $0.777 * *$ \\
\hline & & Rater 3 & $0.694 * *$ & $0.777 * *$ & 1 \\
\hline & Posttest & Rater 1 & 1 & $0.831^{* *}$ & $0.830^{* *}$ \\
\hline & & Rater 2 & $0.831^{* *}$ & 1 & $0.746^{* *}$ \\
\hline & & Rater 3 & $0.830^{* *}$ & $0.746^{* *}$ & 1 \\
\hline
\end{tabular}

** Significant at the $\mathrm{p}<.01$ level 


\section{Appendix B}

Coding Guidelines for Topical Structure Analysis

I. T-units (T)

1. Any independent clauses and all its required modifiers.

2. Any imperative.

II. Parallel Progression (PP)

1. Any sentence topic that is exactly repeated, is a pronominal form, or is a synonym of the immediately preceding sentence topic.

2. Any sentence topic that is a singular or plural form of the immediately preceding sentence topic.

3. Any sentence topic that is an affirmative or negative form of the immediately preceding sentence topic (e.g., artist, no artists).

4. Any sentence topic that has the same head noun as the immediately preceding sentence topic (e.g., the ideas of scientists, the ideas of artists; the contributions by scientists, the contributions made by artists).

III. Sequential Progression (SP)

1. Any sentence topic that is different from the immediately preceding topic, that is, not (1)-(4) in PP.

2. Any sentence topic in which there is a qualifier that so limits or further specifies an NP that it refers to a different referent (e.g., a nation, a very small, multi-racial nation, referring to two different nations).

3. Any sentence topic that is a derivation of an immediately preceding sentence topic (e.g., science, scientists).

4. Any sentence topic that is related to the immediately preceding sentence topic by a part whole relationship (e.g., these groups, housewives, children, old people).

5. Any sentence topic that repeats a part but not all of an immediately preceding sentence topic (e.g., science and art, science, art).

IV. Extended Parallel Progression (EPP)

1. Any sentence topic that is interrupted by at least one sequential topic before it returns to a previous sentence topic.

(Schneider \& Connor, 1990, p. 427)

\section{Copyrights}

Copyright for this article is retained by the author(s), with first publication rights granted to the journal.

This is an open-access article distributed under the terms and conditions of the Creative Commons Attribution license (http://creativecommons.org/licenses/by/3.0/). 